\title{
V. On a voltaic process for etching Daguerreotype plates
}

\author{
W.R. Grove Esq. M.A. F.R.S.
}

To cite this article: W.R. Grove Esq. M.A. F.R.S. (1842) V. On a voltaic process for etching Daguerreotype plates, Philosophical Magazine Series 3, 20:128, 18-24, DOI: 10.1080/14786444208650507

To link to this article: http://dx.doi.org/10.1080/14786444208650507

册 Published online: 01 Jun 2009.

Submit your article to this journal $[\pi$

Џ Article views: 3

Q View related articles $\asymp$ 
Similarly, the two following equations become

$$
\frac{d \mathbf{S}_{a}}{d t}=\varpi \frac{n^{3}}{m^{3}}\left(a^{2}-x^{2}\right), \frac{d \mathbf{S}_{b}}{d t}=\frac{\varpi n^{3}}{m^{3}}\left(b^{2}-y^{2}\right) ;
$$

hence adding and integrating,

$$
\mathrm{S}_{c}+\mathrm{S}_{b}+\mathrm{S}_{c}=\frac{\varpi n^{3}}{m^{3}}\left\{a^{2}+b^{2}+c^{2}-u^{2}\right\} t+\text { constant. }
$$

$\mathrm{XXX}$. Let tangent planes be drawn to the three vertices of $a, b, c$, the semiaxes of the ellipsoid, cutting off from the axis of the impressed moment, three segments whose reciprocals are $\xi, \nu, \zeta$, we shall have $\xi^{2}+v^{2}+\zeta^{2}=$ constant, during the motion,

for $\xi^{2} a^{2}=\cos ^{2} \alpha$; but $\cos ^{2} \alpha=\frac{x^{2}}{u^{2}}$, hence $\xi^{2} u^{2}=\frac{x^{2}}{a^{2}}$. Similarly, $u^{2} u^{2}=\frac{y^{2}}{b^{2}}, \quad \zeta^{2} u^{2}=\frac{z^{2}}{c^{2}} ;$ hence

$$
\xi^{2}+v^{2}+\zeta^{2}=\frac{1}{u^{2}} \text {. }
$$

XXXI. The sum of the squares of the distances of the vertices of the three semiaxes of the ellipsoid from the plane of the impressed moment divided by the corresponding moments of inertia is constant during the motion.

Let $x_{1}$ be the distance of the vertex of $a$ from the plane of the impressed moment, then $x_{1}{ }^{2}=a^{2} \cos ^{2} \alpha$, and $\mathrm{A}=n^{3} a^{2}$; hence $\frac{x_{1}{ }^{2}}{\mathbf{A}}=\frac{\cos ^{2} \alpha}{n^{3}}$.

In like manner,

$$
\frac{y_{1}^{2}}{\mathbf{B}}=\frac{\cos ^{2} \beta}{n^{3}}, \frac{z_{1}^{2}}{\mathbf{C}}=\frac{\cos ^{2} \gamma}{n^{3}} ;
$$

hence

$$
\frac{x_{1}^{2}}{\mathrm{~A}}+\frac{y_{1}^{2}}{\mathrm{~B}}+\frac{z_{1}^{2}}{\mathrm{C}}=\frac{1}{n^{3}} \text {. }
$$

[To be continued.]

V. On a Voltaic Process for Etching Daguerreotype Plates. By W. R. Grove, Esq., M.A., F.R.S., Professor of Experimental Plilosophy in the London Institution*.

$D^{R}$. BERRES of Vienna was the first, I believe, who published a process for etching Daguerreotypes: his method was to cover the plates with a solution of gum-arabic, and then to immerse them in nitric acid of a certain strength.

* From the Proceedings of the London Electrical Society, Part II.; having been read before the Society on the 17 th of August, 1841. Revised by the Author. 
1 have not seen any plates thus prepared, but the few experiments which I have made with nitric acid, have given me a burred and imperfect outline; and $I$ have experienced extreme difficulty of manipulation from the circumstance of the acid never attacking the plate uniformly and simultaneously. My object, however, in this communication, is not to find fault with a process which I have never perhaps fairly tried or seen tried by experienced hands, and the inventor of which deserves the gratitude of all interested in physical science; but to make public another, which possesses the advantage of extreme simplicity, which any one, however unskilled in chemical manipulation, may practise with success, and which produces a perfect etching of the original image; so much so, that a plate thus etched can scarcely be distinguished from an actual Daguerreotype, preserving all the microscopic delicacy of the finest parts of the impression.

One sentence will convey the secret of this process; it is to make the Daguerreotype the anode* of a voltaic combination, in a solution which will not of itself attack either silver or mercury, but of which, when electrolyzed, the anion will attack these metals unequally. This idea occurred to me soon after the publication of Daguerre's process ; but, being then in the country, and unable to procure any plates, I allowed the matter to sleep; and other occupations prevented for some time any recurrence to it. Recently having heard much conversation as to the practicability or impracticability of Daguerreotype engraving, I became anxious to try a few experiments in pursuance of my original notion; and for this purpose applied in several quarters for Daguerreotypes; but, thanks to the exclusiveness of M. Daguerre's patent, I found that to procure a sufficient number of plates for any reasonable chance of success was quite out of the question.

On mentioning the subject to Mr. Gassiot, he with his usual energy and liberality, offered to procure me a sufficiency of Daguerreotypes; and it is owing to his zealous and valuable cooperation that $I$ have been able to get such definite results, as appear worth publication.

Five points naturally present themselves to the consideration of the experimenter on this subject: first, the quantity, of the voltaic current; secondly, its intensity; thirdly, the distance between the anode and cathode; fourthly, the time

* Strictly speaking this is a misapplication of Faraday's term: he applied it to the surface of the electrolyte ; as, however, all continental and many English writers (among whom I may name Whewell) have applied it to the positive electrode, and as an expression is most needed for that, I have not hesitated so to apply it. 
during which the process should be continued; and fifthly, the solution to be employed.

1st. With regard to the first element, or quantity, many previous experiments had convinced me, that, to give the maximum and most uniform quantitative* action of any voltaic combination, the electrodes should be of the same size as the generating plates; in other words, that the sectional area of the electrolyte should be the same throughout the whole voltaic circuit. It seems strange that this point should have been so generally overlooked as it has been : an electrician would never form a battery, one pair of plates of which were smaller than the rest; and yet the electrodes, which offering of themselves a resistance to the current, from the inoxidability of the anode, are, $a$ fortiori, a restriction when of small size, have generally been formed indefinitely smaller than the generating plates; I therefore, without further experiment, applied this principle to the process about to be detailed.

2nd. The intensity of the voltaic current. - Here it appeared to me, that, as in the electrotype, where the visible action is at the cathode, a certain degree of intensity throws down metal as a crystal, an increased intensity as a metallic plate, and a further intensity as a pulverulent mass; that degree of intensity which would show on the negative deposit the finest impressions from the cathode, would also produce on the anode the most delicate excavations, and consequently, an intensity which would just fall short of the point of evolving oxygen from the plate to be etched, would be the most likely to succeed; this point was not, however, adopted without careful experiment, the more so, as in one instance Mr. Gassiot succeeded in procuring a very fair etching with a series of ten pairs of the nitric acid battery; however, the resplts of repeated experiments, in which the intensity has been varied from a series of sixteen pairs to one of the nitric acid battery, were strongly in favour of the above idea, and consequently, went to prove that one pair gives the most efficient degree of intensity for the purpose required.

3rd. The distance between the plates.-As it was proved by De la Rive, that in an electrolytic solution, when the electrodes are at a distance, the action extends a little beyond the parallel lines which would join the bounds of the electrodes, and thus, that the current as it were diverges and converges, it appeared advisable to approximate the electrodes as nearly

* I say quantitative action ; for, where great intensity is required, as in decomposing alkalis, \&c., it may be advisable to narrow the electrodes, so as to present a smaller surface for the reaction of the liberated elements. 
as possible, so as to produce uniformity of action over the whole plate. Provided a solution be used which does not evolve gas at the cathode, I am inclined to think that the plates may be with advantage indefinitely approximated; but as this was not the case with the solution I selected for the greater number of experiments, 0.2 of an inch was fixed on as the distance, in order that the gas evolved from the cathode should not adhere to the anode, and thus interfere with the action.

4th. Time of continuing the operation.-This was a matter only to be decided by experiment, and must vary for the voltaic combination and solution employed. With a single pair of the nitric acid battery, from twenty-five to thirty seconds was, after a great number of experiments, fixed on as the proper time; and as the plate may at any period be removed from the solution and examined, the first experiment should never exceed twenty-five seconds, when, if not complete, the plate may be again subjected to electrolysis.

5th. The solution to be employed.-Here a vast field was open, and still is open to future experimentalists. Admitting the usual explanation of the Daguerreotype, which supposes the light parts to be mercury, and the dark silver, the object was to procure a solution which would attack one of these, and leave the other untouched. If one could be found to attack the silver and not the mercury, so much the better; as this would give a positive engraving, or one with the lights and shadows, as in nature; while the converse would give a negative one. Unfortunately, silver and mercury are nearly allied in their electrical relations. I made several experiments with pure silver and mercury, used as the anode of a voltaic combination; but found, that any solution which would act on one, acted also on the other. All then that could be expected, was a difference of action. With the Daguerreotype plates I have used the following:-

Dilute sulphuric acid, dilute hydrochloric acid, solution of sulphate of copper, of potash, and of acetate of lead. The object of using acetate of lead, was the following:-With this solution, peroxide of lead is precipitated upon the anode; and, this substance being insoluble in nitric acid, it was hoped that the pure silver parts of the plate, being more closely invested with a stratum of peroxide than the mercurialized portions, these latter would, when immersed in this menstruum, be attacked, and thus furnish a negative etching. I was also not altogether without hopes of some curious effects, from the colour of the thin films thus thrown down; here, however, I was disappointed: the colours succeeded each other much as in the steel plate used for the metallochrome; but with in- 
ferior lustre. On immersion in nitric acid of different degrees of dilution, the plates were unequally attacked, and the etching burred and imperfect. Of the other solutions, hydrochloric acid was, after many experiments, fixed on as decidedly the best: indeed, this I expected, from the strong affinity of chlorine for silver.

I will now describe the manipulation which has been employed by Mr. Gassiot and myself, in the laboratory of the London Institution, with very uniform success. A wooden frame is prepared, having two grooves at 0.2 of an inch distance, into which can be slid the plate to be etched, and a plate of platinum of the same size. To ensure a ready and equable evolution of hydrogen, this latter is platinized after Mr. Smee's method; for, if the hydrogen adhere to any part of the cathode, the opposite portions of the anode are proportionably less acted on. The back and edges of the Daguerreotype are varnished with a solution of shell-lac, which is scraped off one edge to admit of metallic connexion being established. The wooden frame with its two plates, is now fitted into a vessel of glass or porcelain, filled with a solution of two measures hydrochloric acid, and one distilled water (sp.gr. 1·1); and two stout platinum wires, proceeding from a single pair of the nitric acid battery, are made to touch the edges of the plates, while the assistant counts the time; this, as before stated, should not exceed thirty seconds. When the plate is removed from the acid, it should be well rinsed with distilled water; and will now (if the metal be homogeneous) present a beautiful sienna-coloured drawing of the original design, produced by a film of the oxychloride formed;-it is then placed in an open dish containing a very weak solution of ammonia, and the surface gently rubbed with very soft cotton, until all the deposit is dissolved; as soon as this is effected, it should be instantly removed, plunged into distilled water, and carefully dried. The process is now complete, and a perfect etching of the original design will be observed; this, when printed from, gives a positive picture, or one which has its lights and shadows as in nature; and which is, in this respect, more correct than the original Daguerreotype as the sides are not inverted; printing can therefore be directly read, and in portraits thus taken, the right and left sides of the face are in their proper position. There is, however, ex necessitate rei, this difficulty, with respect to prints from Daguerreotypes,--if the plates be etched to a depth sufficient to produce a very distinct impression, some of the finer lines of the original must inevitably run into each other, and thus the chief beauty of these exquisite images be destroyed. If, on the other hand, 
the process be only continued long enough to leave an exact etching of the original design, which can be done to the minutest perfection, the very cleaning of the plate by the printer destroys its beauty; and, the molecules of the printing ink being larger than the depth of the etchings, an imperfect impression is produced. For this reason it appeared to me, that at present, the most important part of this process is the means it offers of multiplying indefinitely Daguerreotypes, by means of the electrotype. An ordinary Daguerreotype, it is known, will, when electrotyped, leave a faint impression; but in so doing it is entirely destroyed; and this impression cannot be perpetuated; but one thus etched at the voltaic anode, will admit of any number of copies being taken from it. To give an idea of the perfect accuracy of these, I may mention, that in one $I$ have taken, on which is a sign-board measuring on the electrotype plate 0.1 by 0.06 of an inch, five lines of inscription can, with the microscope, be distinctly read. The great advantages of the voltaic over the chemical process of etching, appear to me to be the following:-

1st. By the former, an indefinite variety of menstrua may be used; thus, solutions of acids, alkalies, salts, more especially the haloid class, sulphurets, cyanurets, in fact, any element which may be evolved by electrolysis, may be made to act upon the plate.

2nd. The action is generalized; and local voltaic currents are avoided.

3rd. The time of operation can be accurately determined; and any required depth of etching produced.

4th. The process can be stopped at any period, and again renewed if desirable.

The time I have given is calculated for experiments made with one pair of the nitric acid battery; it is, however, by no means necessary that this be employed, as probably any other form of voltaic combination may be efficient. It would seem more advisable to employ a diaphragm battery, or one which produces a constant current, as otherwise the time cannot be accurately determined. It is very necessary that the silver of plates subjected to this process be homogeneous. Stria, imperceptible in the original Daguerreotype, are instantly brought out by the action of the nascent anion; probably silver, formed by voltaic precipitation, would be found the most advantageous. I transmit with this paper some specimens of the prints of the etched plates, and of electrotypes taken from them; and in conclusion, would call attention to the remarkable instance which these offer, of the effects of the imponderable upon the ponderable: thus, instead of a plate 


\section{Mr. Smith and Dr. Brett's Additional Remarks}

being inscribed, as "drawn by Landseer, and engraved by Cousins," it would be "drawn by Light, and engraved by Electricity!"

London Institution, Saturday, Aug. 14, 1841.

[With this communication were sent plates etched by the process detailed in the text; electrotype copies from the same; and a considerable number of prints obtained from the former.-SEc. Elect. Soc.]

Postscript by the Author, Nov. 1.-Few of the readers of the Philosophical Magazine will have an opportunity of seeing any specimens of the process, and as the etching is not deep enough to produce impressions sufficient to accompany the paper, I may give an idea of them by saying that in the print of a portrait which I have now before me the whole expression of the features is distinct, the pupil of the eye and the speck of light upon it clearly defined, the gloss of the hair and of the satin stock very accurate. The microscopic details alone appear incapable of transference to paper, but these, as stated above, being absolutely perfect upon the etched plate, I had intended to have directed some experiments to the substitution of more delicate materials than paper and printing-ink for receiving the impressions ; incessant occupations have prevented me, and will I fear for some time.

I would suggest the employment of hyposulphite of soda instead of ammonia to remove the oxychloride.-W. R. G.

VI. Additional Remarks on the alleged Conversion of Carbon into Silicon. By J. Denham Smith, Esq. and R. H. Brett, Ph. D.

To Richard Phillips, Esq., F.R.S.

DeAr Sir,

IN Dr. Brown's observations, p. 389, pres. vol., he states, "For the next experiments, on the ferrocyanide of potassium, let such as are interested in the subject judge whether they be sufficient repetitions of mine. I may mention, in passing, that the two apparatus described in this part of your Correspondents' letter, viz. an iron tube closed with an iron plug, and a gun-barrel protected by luting and well secured at the orifice, were the very instruments that foiled me last November and December. There must be free enough exit for nitrogen," \&c. Now we may observe, that the iron tube with an iron plug was the instrument chiefly employed by us for the purpose of heating ferrocyanide of potassium and carbonate of potash together; nor did we employ this instrument 